\title{
Crustal Structure of the Yamato Basin, Japan Sea, from P-Wave Travel Time Tomography
}

\author{
Laura S. L. Kong, ${ }^{1, *}$ Junzo Kasahara, ${ }^{1}$ and Hiroshi Katao ${ }^{2}$ \\ ${ }^{1}$ Earthquake Research Institute, The University of Tokyo, Bunkyo-ku, \\ Tokyo 113, Japan \\ ${ }^{2}$ Abuyama Seismological Observatory, Disaster Prevention Research Institute, \\ Kyoto University, Takatsuki 569, Japan
}

\begin{abstract}
Tomographic inversions using 1985 DELP Wakashio cruise explosive shot data for P-wave crustal structure beneath the Yamato Basin, Japan Sea, show 55\% average variance reductions for each instrument and final overall rms travel time residuals of $0.07 \mathrm{~s}$. Careful evaluation of model resolution and robustness maximized the volume of well-constrained velocities; anomalies up to $20 \mathrm{~km}$ from the shot lines were found. Velocity increases steadily to $6 \mathrm{~km} / \mathrm{s}$ in the uppermost $2-3 \mathrm{~km}$. Resolved portions from $3-8 \mathrm{~km}$ depth show more seismic heterogeneity, but are small in magnitude. The structure is consistent with that characterizing oceanic seismic layers 2 and 3 , with layer 2 subparallel to the acoustic basement. The thickness of layer 3 is significantly larger, agreeing with thickening trends of layer 3 with increasing crustal thickness found at other oceanic locations. The observed crustal thickness, $4 \mathrm{~km}$ greater than predicted by passive upwelling, suggests the presence of an additional melt-producing mechanism. Convective partial melting at the onset of spreading, combined with rapid basin formation, can provide additional amounts of melt necessary for a thickened crust.
\end{abstract}

\section{Introduction}

Back-arc spreading landward of subducting plates is an essential component of plate tectonic theory. An understanding of the evolution of back-arc rifting can thus provide important insights on plate movement dynamics. To this end, seismic investigations of both active and inactively-spreading rifts to characterize the nature of the plate boundary and underlying crust constitute important observations documenting variations found at different tectonic settings (e.g., Murauchi et al., 1968; Ludwig et al., 1975; Kasahara et al., 1988). Together with marine magnetic anomaly, heat flow, and other geological studies at sea (e.g., Isezaki and Uyeda, 1973; Sclater et al., 1976; Kaneoka et al., 1986), and paleomagnetic and structural geology studies on land (e.g., Otofuji and Matsuda, 1983; Lallemand and Jolivet, 1986), these represent powerful clues critical to unraveling the formation and spreading history of the marginal basin.

Received May 15, 1991; Accepted October 12, 1991

* To whom correspondence should be addressed. Present address: Pacific Tsunami Warning Center, 91-270 Fort Weaver Rd., Ewa Beach, HI96706, U.S.A. 
The Japan Sea is one of the more complex marginal basins in the world, being composed of the Japan Basin, Tartary Trough, Yamato Basin, and Tsushima Basin, and underlain by vastly different crustal structures (Ludwig et al., 1975). The presence of four distinct basins within the Japan Sea, combined with the arcuate shape of the Japanese Islands, suggests a complicated spreading history in which inter-continental and oceanic plate collision, plate subduction, and the responses of several western Pacific trench systems to synchronous tectonic events may have played important roles in the rifting and rotation of individual Japan Sea basins to their present configuration (Otofuji et al., 1985; Tamaki, 1988; Lallemand and Jolivet, 1986; Celaya and McCabe, 1987).

In this paper, we report the results of tomographic inversions for three-dimensional P-wave velocity structure beneath the Yamato Basin, in the southeastern part of the Japan Sea. The study follows up on the findings of previous authors (e.g., Hirata et al., 1987; Katao, 1988; Hirata et al., 1989; Chung et al., 1990) by investigating in detail the dimensions of lateral crustal heterogeneity using travel time data for both along-and off-shot-line ray paths. After first describing the tomographic method and discussing an optimal strategy for model parameterization, results from the inversions are presented along with discussions of model resolution and stability. The proposed similarity of the Yamato Basin crust with oceanic crustal structure is then addressed, and finally, a model for crustal evolution at rifting margins is presented.

\section{The Yamato Basin in the Japan Sea}

The Yamato Basin is a northeast-trending topographic depression located in the southeastern part of the Japan Sea marginal basin (Fig. 1). The flat, smooth seafloor

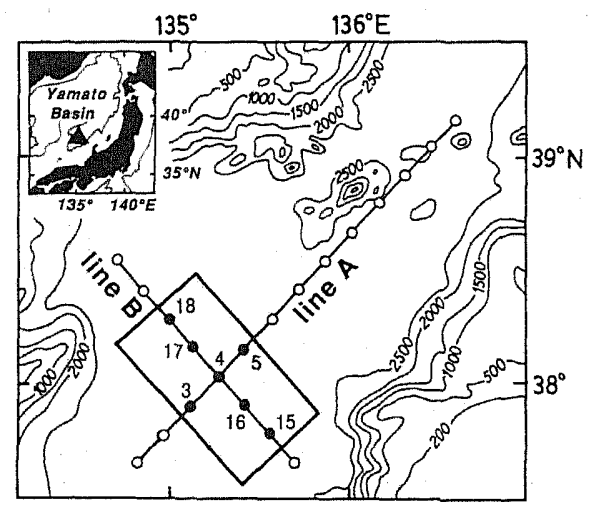

Fig. 1. Configuration of DELP-85 seismic experiment (Hirata et al., 1987) in the Yamato Basin of the Japan Sea (see inset for location). Explosive charges were detonated parallel to the relic spreading axis along Line $\mathrm{A}$, and perpendicular to the axis along Line B, to instruments (solid and open circles) spaced $20 \mathrm{~km}$ apart. The study area for this paper is outlined by the box; OBS instruments used are indicated by solid circles and instrument numbers. Bathymetry is contoured at $500 \mathrm{~m}$ intervals. 
(depth of about $3,000 \mathrm{~m}$ ) is floored by up to about $1 \mathrm{~km}$ of Miocene to Pleistocene sediments (Tokuyama et al., 1987; Tamaki, 1988), and the Basin is characterized by weak magnetic anomalies (Isezaki and Uyeda, 1973). The age and manner of formation are controversial. The clockwise rotation of southwest Japan $15 \mathrm{Ma}$ (Otofuji and Matsuda, 1983, 1984; Hayashida and Ito, 1984), based on paleomagnetic data, has been used to argue for the rapid opening of the Japan Sea and Yamato Basin by back-arc spreading (Otofuji and Matsuda, 1984; Otofuji et al., 1985). In contrast, Lallemand and Jolivet (1986) propose, from structural geology data, formation of a pull-apart basin along two right-lateral shear zones off Korea and northeast Honshu, followed by back-arc spreading in the middle Miocene after $21 \mathrm{Ma}$ due to the extensional stress field present behind the subducting Pacific plate. Celaya and McCabe (1987) suggest a two-stage rifting process with the Japan Basin formed initially followed by the spreading and rotation of the Yamato Basin in the early Miocene in response to an oceanic arc collision in western Hokkaido. Tamaki (1988) estimated the age of the Yamato Basin to be 10-30 Ma from sediment stratigraphic, basement depth, and heat flow data, and suggested that the back-arc spreading was related to the collision of the Indian and Eurasian continental plates. A sharp change in benthic fauna type (Chinzei, 1986), and the uplift of sedimentary units in central Japan (Hayakawa and Takemura, 1987), is consistent with the opening about $15 \mathrm{Ma}$.

Spreading may have taken place along the northeast-trending Yamato Basin Ridge, which can be traced for about $400 \mathrm{~km}$ along-strike and varies from 10 to $20 \mathrm{~km}$ in width; seismic reflection records show the ridge to be offset by transverse faults possibly active during spreading, though thrust faulting appears to be occurring at present (Kimura et al., 1987). Based on the identification of fold and thrust structures in seismic reflection profiles of the continental slope off northeastern Japan (Kimura et al., 1987; Tamaki, 1988), it is thought that the present regional stress field is compressional. K/Ar and ${ }^{40} \mathrm{Ar}-{ }^{39} \mathrm{Ar}$ dating of the Yamato Seamount chain (6-18 Ma; Kaneoka et al., 1986; Kimura et al., 1987), located near the fossil spreading axis and striking east-northeast subparallel to it, indicates that they formed synchronously with or soon after the cessation of spreading. A halt to active spreading before full transition to normal ocean basin spreading is also consistent with ${ }^{87} \mathrm{Sr} /{ }^{86} \mathrm{Sr}$ ratios from the Yamato Seamount chain, which still show a component of arc volcanism (Kaneoka et al., 1986).

\section{DELP-85 Seismic Experiment}

As part of the 1985 Japan Dynamics and Evolution of Lithosphere Project (DELP-85), seismic refraction and reflection data were collected from the central Yamato Basin of the Japan Sea (Fig. 1). Seismic lines were shot both along $(230 \mathrm{~km}$ in length, Line A) and across (130 km in length, Line B) the relic spreading axis to ocean bottom seismometers (OBS) spaced $20 \mathrm{~km}$ apart (Hirata et al., 1987). The OBSs, belonging to the Earthquake Research Institute (Kasahara et al., 1979, 1985) and the Geophysical Institute of the University of Tokyo (Shimamura and Asada, 1974), were equipped with vertical and horizontal geophones; four of the 20 OBSs were digitally-recording instruments. Explosive source shot spacing averaged $2.3 \mathrm{~km}$ and shot sizes ranged from 5 to $25 \mathrm{~kg}$; several large shots $(300-500 \mathrm{~kg})$ were also detonated to record seismic Pn energy

Vol. 39, No. 3, 1991 
out to distances greater than $200 \mathrm{~km}$. In addition, air gun data (20 liter volume, $350 \mathrm{~m}$ shot spacing) recorded by the OBSs and a 6-channel multi-channel seismic streamer along both explosive source lines provided excellent control on the sedimentary structure and topography of the acoustic basement (Tokuyama et al., 1987).

Several authors have reported results based on subsets of the DELP-85 data (Katao, 1988; Hirata et al., 1989; Chung et al., 1990). Using foward modeling of the travel times and waveforms, two-dimensional models parameterized by layers and velocity gradients were derived for the structure beneath Lines A and B. Their findings suggested, in agreement, that the crustal structure resembled that of oceanic crust, but with a thickness $(11-15 \mathrm{~km})$ twice that of normal oceanic crust. The layered structure suggested considerable velocity homogeneity in the along-axis (Line A), P-wave structure. In contrast along Line $\mathrm{B}$, crossover distances of $\mathrm{Pn}$ and critical distances of $\mathrm{PmP}$ across the axis were significantly smaller than those observed along the axis, suggesting up to a $3 \mathrm{~km}$ decrease in crustal thickness away from the axis, and/or the presence of up to $10 \% \mathrm{P}$-wave anisotropy with the fast velocity direction parallel to the inferred spreading direction. Hirata et al. (1989) proposed that the large crustal thickness and construction of the Yamato Seamount chain was due to the formation of sills within the crust that resulted from the abrupt halt of spreading about $15 \mathrm{Ma}$ when the regional stress field changed from extension to compression.

\section{Tomographic Inversion of Yamato Basin Data}

\subsection{Travel time data}

In order to investigate spatial velocity variations, especially within seismic layer 2 and the upper portion of layer 3, tomographic inversions using P-wave travel time data for three-dimensional velocity structure over a 40 by $20 \mathrm{~km}$ area centered about the axis have been carried out (Table 1). The tomographic technique, where the velocity model is parameterized by a three-dimensional grid, is desirable since the dimensions of anomalous regions of velocity can be constrained, thus distinguishing it from the layered velocity-depth solutions reported previously. Because of the configuration of sources and receivers, however, perfect resolution of the entire target volume is precluded (Fig. 2). However, careful evaluation of model resolution and robustness allows portions of the off-shot-line velocity structure to be reasonably well-constrained.

The locations of the 95 explosive shots $(5-25 \mathrm{~kg}$ shot sizes) and seven instruments used for the final inversion solution are shown in Fig. 2(a); travel time observations for both along- and off-shot-line ray paths totaled 450 using only shots with two or more travel times. Figure 2(b) shows an areal map of the ray path coverage for the travel time data used in the final inversion solution. Corrections for shot instant and instrument clock drift (typically $0.02 \mathrm{~s}$ /day) were applied to the digitized data files prior to the picking of $\mathrm{P}$-wave phases. Travel times could easily be identified on the vertical seismometer to within $0.02 \mathrm{~s}$ (Fig. 3); less certain picks were linearly downweighted in the inversion program. Short locations were determined by LORAN C combined with NNSS satellite navigation (typical error of $100 \mathrm{~m}$ ). Instrument locations were based on the LORAN C deployment and recovery locations and are accurate to within $150 \mathrm{~m}$; instrument depths were taken from a $12 \mathrm{kHz}$ Precision Depth Recorder. 

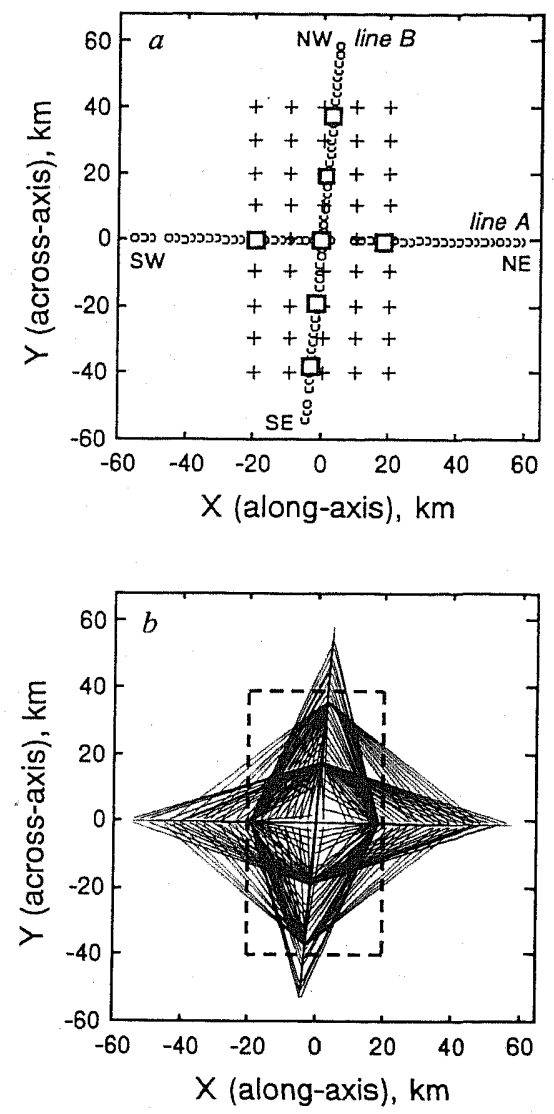

Fig. 2. (a) Configuration of sources (circles) and receivers (squares), and areal distribution of velocity parameters (crosses) used in tomographic inversion 1. In the depth direction, velocity was solved for at $Z=0,2,4,6$, and $8 \mathrm{~km}$. Origin corresponds to the location of YB 4. (b) Ray path coverage for the travel time data. used in the tomographic study assuming a homogeneous velocity structure. Because of the non-uniform ray distribution within the velocity grid region (outlined by heavy dashed line), resolution of the entire target volume is not possible.

Water path corrections to the seafloor were calculated using estimates of the range-dependent ray parameter and the bathymetry along the shot line (Purdy, 1982). Errors resulting from uncertainties in water depth are thought to be minimal $(<0.025 \mathrm{~s})$ because of the flat seafloor. In addition, sediment velocities estimated from closely-spaced air gun and multi-channel reflection data (Katao, 1988; Fig. 4) were used to determine travel time and range corrections through the sediments to a nominal acoustic basement. Removal of the sedimentary column prior to inversion is essential, because undulations within the sediments and at the acoustic basement cannot be adequately described by the 
Table 1. Tomographic inversion summaries.

\begin{tabular}{|c|c|c|c|c|c|c|c|}
\hline Inversion ${ }^{a}$ & $\begin{array}{l}\text { Start model } \\
\text { datum }(\mathrm{km})\end{array}$ & $\begin{array}{c}\Delta x, \Delta y, \Delta z(\mathrm{~km}) \\
n x, n y, n z^{\mathrm{c}}\end{array}$ & $\begin{array}{l}\text { Trace, } k \\
k / m(\%)^{\mathrm{d}}\end{array}$ & $\begin{array}{l}\mathrm{rms}_{\mathrm{i}}(\mathrm{s}) \\
\mathrm{rms}_{\mathrm{f}}(\mathrm{s})\end{array}$ & $\begin{array}{l}s^{2}{ }_{i}\left(s^{2}\right) \\
s^{2}{ }_{f}\left(s^{2}\right)\end{array}$ & $\begin{array}{c}\text { Variance } \\
\text { reduction (\%) }\end{array}$ & $\begin{array}{c}\Delta v \\
(\mathrm{~km} / \mathrm{s})^{\mathrm{e}}\end{array}$ \\
\hline 1 & $\begin{array}{l}1 \mathrm{D} \\
4.20\end{array}$ & $\begin{array}{c}10,10,2 \\
5,9,5\end{array}$ & $\begin{array}{l}55 \\
24\end{array}$ & $\begin{array}{l}0.18 \\
0.07\end{array}$ & $\begin{array}{l}0.031 \\
0.004\end{array}$ & 86 & - \\
\hline 2 & $\begin{array}{c}1 \mathrm{D} \\
4.20\end{array}$ & $\begin{array}{c}5,5,2 \\
9,17,5\end{array}$ & $\begin{array}{r}64 \\
8\end{array}$ & $\begin{array}{l}0.18 \\
0.05\end{array}$ & $\begin{array}{l}0.031 \\
0.003\end{array}$ & 91 & 0.38 \\
\hline 3 & $\begin{array}{l}2 \mathrm{D} \\
4.20\end{array}$ & $\begin{array}{c}10,10,2 \\
5,9,5\end{array}$ & $\begin{array}{l}54 \\
24\end{array}$ & $\begin{array}{l}0.18 \\
0.07\end{array}$ & $\begin{array}{l}0.034 \\
0.005\end{array}$ & 86 & 0.16 \\
\hline 4 & $\begin{array}{l}1 \mathrm{D} \\
4.20\end{array}$ & $\begin{array}{c}8,8,2 \\
7,11,5\end{array}$ & $\begin{array}{l}61 \\
16\end{array}$ & $\begin{array}{l}0.18 \\
0.06\end{array}$ & $\begin{array}{l}0.031 \\
0.003\end{array}$ & 89 & 0.34 \\
\hline 5 & $\begin{array}{c}1 \mathrm{D} \\
4.20\end{array}$ & $\begin{array}{c}12,12,2 \\
5,7,5\end{array}$ & $\begin{array}{l}50 \\
29\end{array}$ & $\begin{array}{l}0.18 \\
0.07\end{array}$ & $\begin{array}{l}0.031 \\
0.005\end{array}$ & 85 & 0.28 \\
\hline 6 & $\begin{array}{c}1 \mathrm{D} \\
4.20\end{array}$ & $\begin{array}{c}10,10,3 \\
5,9,4\end{array}$ & $\begin{array}{l}50 \\
28\end{array}$ & $\begin{array}{l}0.18 \\
0.07\end{array}$ & $\begin{array}{l}0.031 \\
0.005\end{array}$ & 83 & 0.22 \\
\hline 7 & $\begin{array}{l}1 \mathrm{D} \\
4.20\end{array}$ & $\begin{array}{c}10,10,4 \\
5,9,3\end{array}$ & $\begin{array}{l}45 \\
33\end{array}$ & $\begin{array}{l}0.18 \\
0.07\end{array}$ & $\begin{array}{l}0.034 \\
0.005\end{array}$ & 85 & 0.28 \\
\hline 8 & $\begin{array}{l}1 \mathrm{D} \\
4.64\end{array}$ & $\begin{array}{c}10,10,2 \\
5,9,5\end{array}$ & $\begin{array}{l}57 \\
25\end{array}$ & $\begin{array}{l}0.17 \\
0.07\end{array}$ & $\begin{array}{l}0.030 \\
0.005\end{array}$ & 84 & 0.18 \\
\hline $9^{f}$ & $\begin{array}{l}2 \mathrm{D} \\
4.20\end{array}$ & $\begin{array}{c}10,10,2 \\
5,9,5\end{array}$ & $\begin{array}{l}54 \\
24\end{array}$ & $\begin{array}{l}0.18 \\
0.07\end{array}$ & $\begin{array}{l}0.034 \\
0.005\end{array}$ & 85 & 0.19 \\
\hline
\end{tabular}

a Inversions use 450 observations from 95 sources to 7 instruments. b $1 D=$ one-dimensional model (Fig. 5). $2 \mathrm{D}=$ two-dimensional model for $Z=0$ layer using Katao (1988) velocities. ${ }^{c}$ Nodal spacing and number of nodes. Node placements centered around $(X, Y)=(0,0)$, and start downwards from $Z=0$. For example, Run 1 node placements are $X=-20,-10,0,10,20 ; Y=-40,-30,-20,-10,0,10,20,30,40$; and $Z=0,2,4,6,8$. ${ }^{\mathrm{d}}$ Percentage of linearly independent parameters, where $m$ is the number of velocity parameters. 'Mean difference in absolute velocity, relative to Inversion 1, for Inversion 1 nodes having resolution $\geq 0.5$. $\mathrm{f}$ Velocities at $Z=0$ fixed throughout inversion.

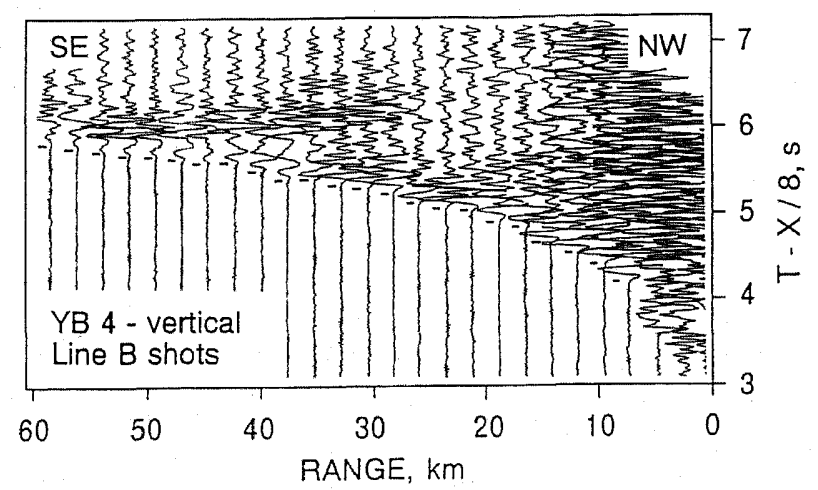

Fig. 3. Typical example of high-quality data recorded on the vertical seismometer of the OBSs. P-wave arrivals, indicated by the dashed line, are easily picked because of the high signal-to-noise ratio. Seismograms displayed were low-pass filtered to $30 \mathrm{~Hz}$ and plotted with a reduction velocity of $8 \mathrm{~km} / \mathrm{s}$. 

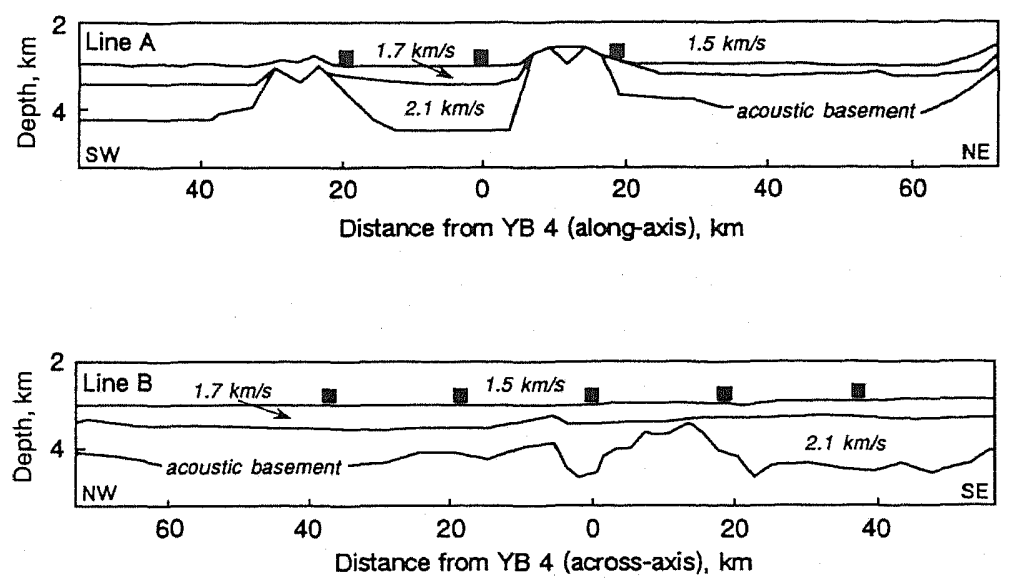

Fig. 4. Seismic structure used to compute water path and sediment corrections. Average $\mathrm{P}$-wave velocities and layer topography were determined from air gun shots to the OBSs and multi-channel seismic reflection data along Lines A and B (Katao, 1988). Buried seamounts are most easily identified in the acoustic basement profile. Solid squares show instrument locations. Depth corresponds to the distance below sea level.

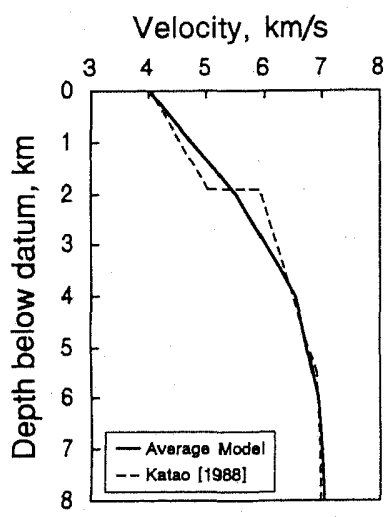

Fig. 5. Average one-dimensional velocity model (solid line) used as the starting model in the tomographic inversions. This structure compares well with that found beneath YB 4 by Katao (1988) (dash line). Depth is measured relative to a horizontal datum of $4.2 \mathrm{~km}$ below sea level.

optimal inversion model parameterization for the crust (areal grid-interval of $10 \mathrm{~km}$ ).

In total, the mean range and time corrections to place the source at the nominal acoustic basement were $1,093 \pm 168 \mathrm{~m}$ and $2.63 \pm 0.22 \mathrm{~s}$, respectively. Reduced travel time residuals, relative to an average P-wave structure for the Yamato Basin (Fig. 5), are shown in Fig. 6(a). Variations in the magnitude of the travel time residuals along a single shot line to one instrument $(0.2-0.3 \mathrm{~s}$, relative to the average model, Fig. 5)

Vol. 39, No. 3, 1991 

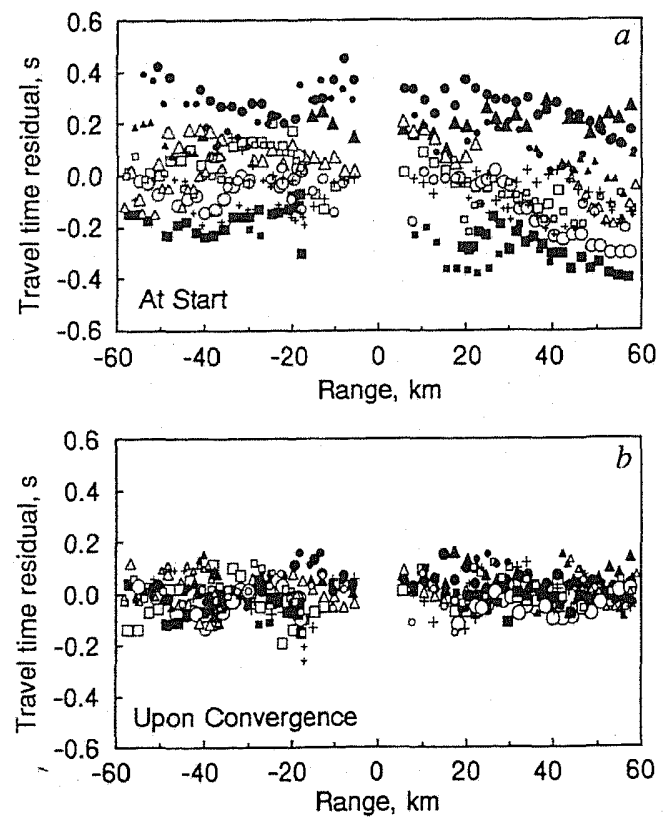

Fig. 6. (a) Water-and sediment-path corrected travel time residuals for a source and receiver at the acoustic basement relative to the $1 \mathrm{D}$ starting model in Fig. 5. The largest positive residuals are associated with YB 4 (solid circles) and YB 15 (solid triangles), suggesting that the shallowmost region beneath the instruments have velocities slower than the average model, while negative residuals associated with YB 5 (solid squares) indicate faster-than-average velocities. Travel time residuals for other instruments (YB 3, open circles; YB 16, crosses; YB 17, open squares; and YB 18, open triangles) have means near zero. Note that a large amount of the absolute travel time residual may be the result of uncertainties in the assumed sedimentary velocity-depth structure used to correct the travel times to the acoustic basement. The overall mean and standard deviation for all shots to all instruments was $0.00 \pm 0.18 \mathrm{~s}$. Larger symbols correspond to shots from Line B and smaller symbols from Line A. Negative ranges, measured from YB 4, correspond to the southwest and southeast portions of Lines A and B, respectively. (b) Inversion 1 travel time residuals at convergence. The overall mean and standard deviation was $0.00 \pm 0.07$ s. Symbols same as in (a). See Fig. 9 for a summary of travel time residual and variance reductions for each instrument.

indicate the presence of as yet unmodeled heterogeneity. Note that uncertainties in the velocity-depth structure of the sediments, which could lead to travel time correction errors of tenths of seconds, may still be present in the travel time data corrected to the nominal acoustic basement. However, by selecting a velocity model parameterization depth grid interval of $2 \mathrm{~km}$, it is argued that travel time uncertainties will primarily be manifested in the estimates of the $0 \mathrm{~km}$ depth velocity parameters which describe the 
variations in velocity near the sediment/acoustic basement interface.

\subsection{Inversion method}

The tomographic technique used to solve for P-wave velocity perturbations to an initial structure employs travel time residual data from shots. The algorithm is a modification of a simultaneous earthquake relocation and velocity inversion method first developed by Thurber (1981). The velocity model is parameterized by a discrete set of velocities on a three-dimensional grid, with the velocity at any position defined as a weighted average of the surrounding eight nodal velocities; a natural consequence of this is that a continuous velocity field can be derived. The procedure incorporates a computationally efficient and fast approximate ray tracing routine which can calculate accurate travel times over local distances $(<0.01 \mathrm{~s}$ for ray paths of less than $35 \mathrm{~km}$; Thurber, 1981). In the Yamato Basin study, only shots at ranges less than $60 \mathrm{~km}$ are used and travel times were linearly downweighted for ranges greater than $40 \mathrm{~km}$ to ensure that the closer data, for which travel times can be most accurately computed using the ray tracer, are given the most weight.

Velocity perturbations to an initial model from observed travel time residuals are estimated through the iterative solution of a linearized system of equations. For an assumed velocity model, travel time residuals are calculated by solving the forward problem for known source-receiver combinations. The travel time partial derivatives with respect to each velocity parameter are computed next, and linear inverse theory is used to obtain a set of parameter adjustments and a new estimate of the velocity model. This process is repeated until convergence is achieved, in this case specified by an $F$-test on the ratio of iteration step variances to determine if reductions in variance are significant at the $95 \%$ level. Because the use of a finite set of $n$ data to estimate a discrete set of $m$ velocity parameters, which describe a naturally continuous function, will almost always lead to the poor resolution of some model parameters, the problem in general will be underdetermined.

In order to avoid solution instability resulting from near-zero singular values (Aki and Lee, 1976; Crosson, 1976), the Levenberg-Marquardt method of damped least squares is employed to damp spuriously large perturbations associated with poorly constrained parameters. By including a damping parameter, $\lambda^{2}$ (Levenberg, 1944; Marquardt, 1963), in the inversion and thus minimizing the weighted sum of travel time residuals and solution vectors, the eigenvalue spectrum is modified so that small eigenvalues do not produce large velocity perturbations, while for large eigenvalues the addition of $\lambda^{2}$ changes little the magnitude of the adjustment. The choice of $\lambda$ is motivated by the desire to obtain stable solutions with reasonable variances; resolution is maximized for $\lambda=0$ at the expense of larger covariances, while for large $\lambda$, travel time residuals are minimized but parameter resolution decreases; in this study, a value of 2.0 was used for the damping parameter.

The singular value decomposition of the travel time partial derivative matrix provides quantitative information on the solution stability, and parameter resolution and error (Wiggins, 1972; Jackson, 1972, 1979). The resolution matrix, $R$, is a function of the data kernel and a priori information, and as such measures how well a model and distribution of data will estimate the true structure. In the ideal case, when $R=I$, 
the Identity matrix, the model will be perfectly resolved by a given data kernel. The covariance matrix maps the way data error affects the determination of a model parameter. The square root of the diagonal elements of the covariance matrix gives an estimate of the standard error in estimating each parameter. In a comparison using synthetic data, however, Thurber (1981) found that the actual velocity errors were poorly correlated with the standard error, and that the mean absolute error was nearly twice the mean standard error. Based on this, it is assumed that the individual standard errors calculated from the covariance matrix for each velocity node are unreliable, and instead estimate the mean absolute velocity error for the entire solution as being twice the mean standard error; for the Yamato Basin study, the error in parameter space is about $0.2-0.3 \mathrm{~km} / \mathrm{s}$, or $3-4 \%$ deviation from the starting model for well-resolved regions.

\subsection{Model parameterization}

A model parameterization which considers the distribution and density of seismic ray paths, and investigates anomalies of dimensions consistent with the scale of existing heterogeneity while maximizing the volume of acceptable resolution, will result in an optimal inversion solution. Several quantitative measures that are independent of the actual travel time data values can be calculated and used to evaluate the desirability of a given velocity parameterization. The derivative weight sum (DWS) gives a quantitative representation of ray density near a velocity parameter (C. H. Thurber, personal communication, 1988; Toomey and Foulger, 1989; Kong, 1990), and is examined to ensure that velocity nodes are adequately sampled by the available source-receiver ray paths (Fig. 7). For an ideal data kernel and model, the DWS, which is dependent on the increment of sampling in the ray tracing routine, will be smooth and slowly varying. This will lead to a minimum of poorly sampled nodes and thus avoid solutions containing spurious nodes of unperturbed velocity.

Similarly, the complete resolution matrix associated with each velocity parameter location can be examined to ensure that the velocity estimated represents a unique
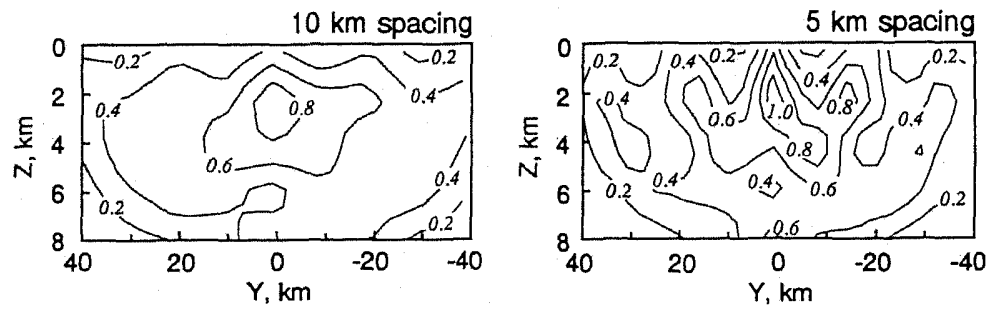

Fig. 7. Vertical sections of DWS (normalized to the largest value for each section) along the $Y$-direction at $X=0$ for inversions using $10 \mathrm{~km}$ (inversion 1) and $5 \mathrm{~km}$ (inversion 2) grid spacings in the $X$ - and $Y$-directions. Because the DWS for the $5 \mathrm{~km}$ spacing is highly variable, sampling of adjacent nodes in some areas may be inadequate, thereby resulting in non-localized averages and spuriously perturbed velocity estimates. Areal distances $(X$ and $Y)$ are measured from YB 4 , and $Z$ corresponds to the depth below a $4.2 \mathrm{~km}$ horizontal datum in Figs. 7 and 8. 
$10 \mathrm{~km}$ spacing
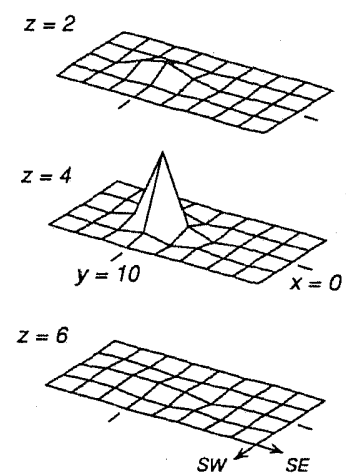

$5 \mathrm{~km}$ spacing
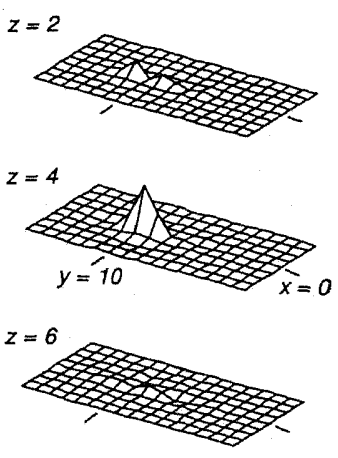

Fig. 8. Resolution matrix for the velocity node at $(X, Y, Z)=(0,10,4 \mathrm{~km})$ for inversions 1 and 2 using 10 and $5 \mathrm{~km}$ grid spacings, respectively. The magnitudes of elements in the resolution matrix are plotted at the velocity parameter nodal locations, measured from YB 4, for horizontal planes at depths of 2, 4, and $6 \mathrm{~km}$. Comparison shows that velocity will be more uniquely-resolved using a $10 \mathrm{~km}$ spacing since the estimate respresents a localized average, whereas the values of the resolution matrix adjacent to the $(0,10,4)$ node using a $5 \mathrm{~km}$ spacing are significantly large, as well as asymmetric in the 2 and $6 \mathrm{~km}$ depth planes. Although the width of the resolving kernel (non-zero values of the resolution matrix) for both inversions appears to be equal $(20 \mathrm{~km}$ in the $Y$-direction), the use a $10 \mathrm{~km}$ grid spacing will give truer estimates of each velocity parameter because its resolving kernels are more compact.

localized average and is not significantly affected by the magnitudes of off-diagonal elements (Fig. 8). For an underdetermined problem where the number of velocity nodes $m$ is greater than the number of linearly independent parameters $k, R$ will in general have non-zero off-diagonal components. In this case, an optimal model parameterization will be one in which $R$ is compact and approximates a $\delta$-like resolving kernel (Wiggins, 1972). The trace of the resolution matrix, $\operatorname{tr}(R)$ or the sum of the diagonal elements of $R$, gives an estimate of $k$, and can be used to calculate the percentage of linearly independent parameters $(\mathrm{k} / \mathrm{m})$. A comparison of this percentage for two models, such as one with a coarse and one with a fine nodal spacing, would test whether a finer model parameterization is more desirable; a decrease in the percentage implies that additional independent information cannot be extracted if the velocity model is parameterized more finely (Toomey and Foulger, 1989; Kong, 1990).

Several model parameterizations were tested to determine the optimal configuration of velocity parameters for the Yamato Basin data set. As an illustration, the DWS and resolution matrices for two models, one with areal nodal locations spaced $10 \mathrm{~km}$ apart (our preferred parameterization, inversion 1) and one with nodes only $5 \mathrm{~km}$ apart (inversion 2), are shown in Figs. 7 and 8 . Velocity node placements within each nodal column (in the depth, or $Z$ direction) were identical for both models. Examination of the $10 \mathrm{~km}$ model shows that the DWS varies smoothly and slowly throughout the

Vol. 39, No. 3, 1991 
section, and that the resolution matrix is compact. In contrast, the DWS for the $5 \mathrm{~km}$ model varies substantially from node to node (Fig. 7), implying that non-localized averages will occur and explaining why the magnitudes of off-diagonal elements of the resolution matrix are large in the $Z=4$ panel and bi-modal in the $Z=2$ panel (Fig. 8). In addition, although the number of velocity parameters is much larger for the $5 \mathrm{~km}$ model, its trace is only 64 (for the $10 \mathrm{~km}$ model, the trace is 55), and the percentage of linearly independent parameters decreases from 24 to $8 \%$ with a finer parameterization (Table 1). Based on these considerations, the $10 \mathrm{~km}$ areal spacing was adopted as the preferred velocity parameter configuration for the tomographic inversions. This spacing is also in agreement with the wavelength of subsurface features, such as seamounts, identifiable in the seismic reflection records (Fig. 4).

In the tomographic inversion method, velocity perturbations are initially estimated from travel time residuals calculated relative to a plane-layered model that reasonably approximates the true velocity structure. The adopted starting model represents the average P-wave structure beneath YB 4 in the Yamato Basin and is based on the one-dimensional (1D) gradient model derived by Katao (1988) from the forward modeling of travel times and amplitudes (Fig. 5). The use of a 1D initial model is adequate because the distribution of model parameters is relatively broad and velocity perturbations from the starting model are small. Comparison of tomographic inversion solutions obtained with one- and two-dimensional (2D) starting models using the same nodal configuration (inversions 1 and 3, Table 1) gave similar patterns and locations of heterogeneity with a mean velocity difference between the models that was less than the estimated solution error; an $F$-test on the ratio of final rms travel time residuals and data variances for the two inversions indicates that the differences are insignificant at the $95 \%$ confidence level for the number of degrees of freedom.

Velocity parameters were placed every $10 \mathrm{~km}$ in the along-axis $(X)$ and across-axis $(Y)$ directions to encompass a 40 by $20 \mathrm{~km}$ area about the relic spreading axis (Fig. 2(a)). Greater ray path coverage was possible in the across-axis direction because of the larger amount of available OBS data. Within each nodal column, velocity nodes were placed at depths of $Z=0,2,4,6$, and $8 \mathrm{~km}$ beneath a horizontal datum located $4.2 \mathrm{~km}$ below the sea surface; the $4.2 \mathrm{~km}$ depth corresponds to the average depth for the acoustic basement. The nodes at 0 and $2 \mathrm{~km}$ depth were used to approximate the acoustic basement and model the steep velocity gradients found in the shallowmost crust. In addition, vertical-incidence station corrections based on instrument depth and sediment layer structure were calculated so as to also place the receiver at the acoustic basement. Ray tracing through the along- and across-axis structure from Katao (1988) shows that rays penetrate only to depths of about $9 \mathrm{~km}$ at ranges of $60 \mathrm{~km}$, thus limiting the depth dimension of the imaging volume to $8 \mathrm{~km}$.

\subsection{Results}

The preferred tomographic inversion solution (inversion 1) using the 95 shot sources to seven OBSs is summarized in Figs. 9-12 and Table 1. This solution appears to be robust (see next section) and is representative of many other inversions that were carried out. The final rms travel time residual was $0.07 \mathrm{~s}$ after four iterations. Figure 6 shows plots of all travel time residuals at the start and upon convergence to the final model, 


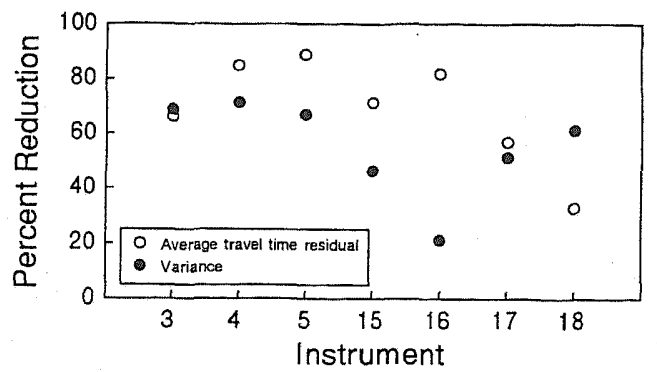

Fig. 9. Inversion 1 average travel time residual and variance reductions, relative to the starting model, for each instrument at convergence.
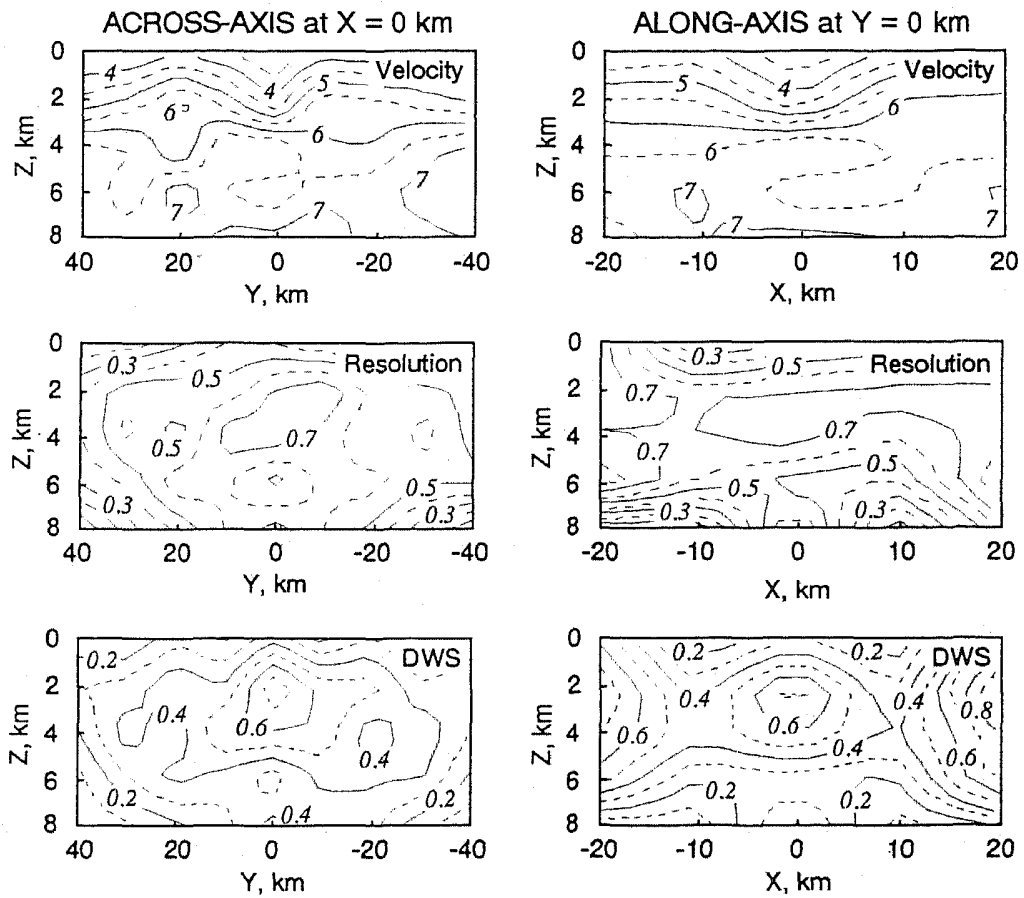

Fig. 10. Across- and along-axis structure beneath Lines $\mathrm{B}(X=0 \mathrm{~km})$ and $\mathrm{A}$ $(Y=0 \mathrm{~km})$, respectively, for inversion 1 . In general, velocity is resolvable when ray path coverage (as indicated by the DWS) is adequate, and the value of resolution is greater than 0.5 . Velocity is contoured every $0.5 \mathrm{~km} / \mathrm{s}$. Resolution, represented as the value of the diagonal element of the resolution matrix at a particular nodal location, is contoured at intervals of 0.1. DWS, normalized to the largest value in the complete DWS matrix, is contoured at intervals of 0.1 . The $Z$-axis represents the depth below a $4.2 \mathrm{~km}$ datum, with $X$ - and $Y$-distances measured from YB 4. See text for discussion, and Figs. 2 and 4 for profile and seamount locations.

Vol. 39, No. 3, 1991 


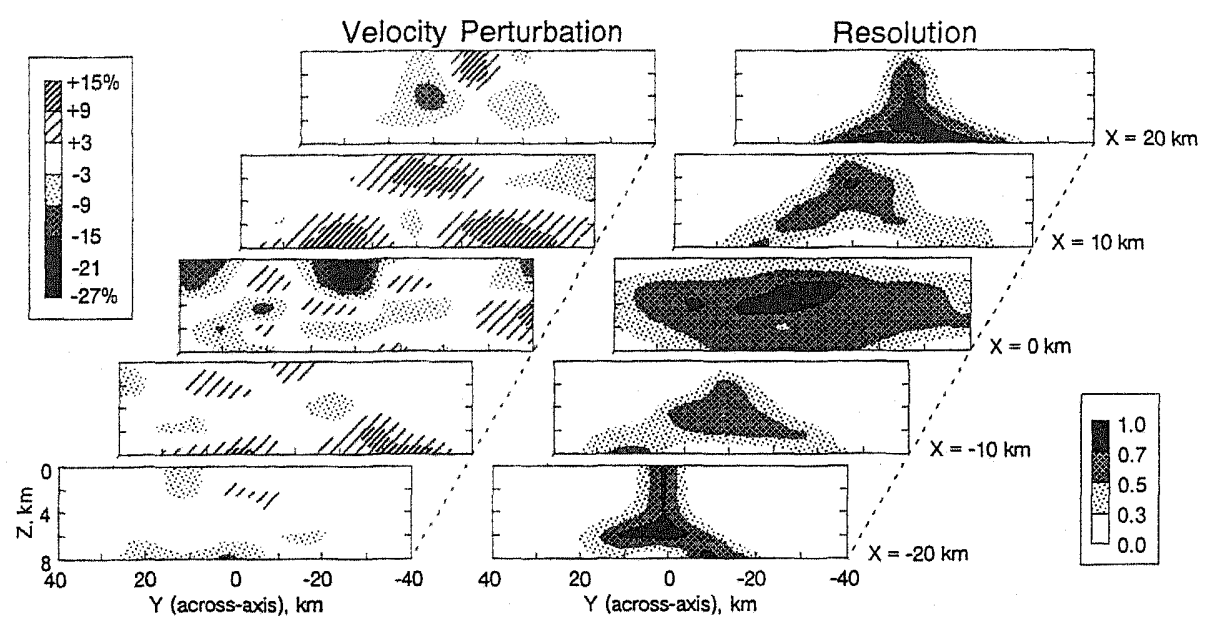

Fig. 11. Vertical sections summarizing inversion 1 results in the across-axis dimension at the along-axis locations of $X=-20,-10,0,10$, and $20 \mathrm{~km}$. Changes in velocity that are greater than $4 \%$ when resolution is greater than 0.5 are regarded as significant. Velocity perturbations are contoured as the percent change from the average starting model in $6 \%$ intervals; negative values indicate velocities less than the average model in Fig. 5. Depth is the distance below a $4.2 \mathrm{~km}$ horizontal datum, with areal distances measured from YB 4. See text for discussion and Fig. 2(a) for location of profiles.

indicating an $86 \%$ overall reduction in variance. Figure 9 shows a summary of the reductions in the average travel time residual and variance for each instrument from start to solution convergence; an analysis of this type describes more realistically the reduction of variance resulting from the better fit of the solution to the data since the larger overall initial data variance (due in part to uncertainties in the sediment path correction of the travel times to the acoustic basement, see Fig. 6(a)) is not used. Upon convergence, the reduction in variance for each OBS ranged from 21 to $71 \%$ (average reduction of $55 \%$ from 0.009 to $0.004 \mathrm{~s}^{2}$ ), and the average OBS travel time residual was reduced by 33 to $89 \%$. Because of the distribution of shots and receivers, velocity is not resolvable at a number of nodes within the $40 \times 20 \times 8 \mathrm{~km}$ volume. In general, the best-resolved velocity parameters are located along (Fig. 10), or near to the shot lines, and encompass a larger volume in the across-axis direction (up to $\pm 20 \mathrm{~km}$, Fig. $11)$ than in the along-axis direction $( \pm 10 \mathrm{~km}$, Fig. 12). Areas of the solution where the resolution of the node (diagonal element of the resolution matrix) is greater than 0.5 can be considered to be most reasonable; in other areas (resolution «0.5-white areas in resolution profiles of Figs. 11 and 12), velocity may be unreliable since significant averaging over neighboring nodes may render the estimate non-unique or spurious.

In general, the $\mathrm{P}$-wave structure of the uppermost crust is characterized by a steady increase in velocity to about $5.5-6.0 \mathrm{~km} / \mathrm{s}$, with the layer being relatively uniform in thickness $(2-3 \mathrm{~km})$ and subparallel to the acoustic basement. Careful testing of the robustness of the uppermost $\mathrm{P}$-wave velocities, as well as comparison with other 


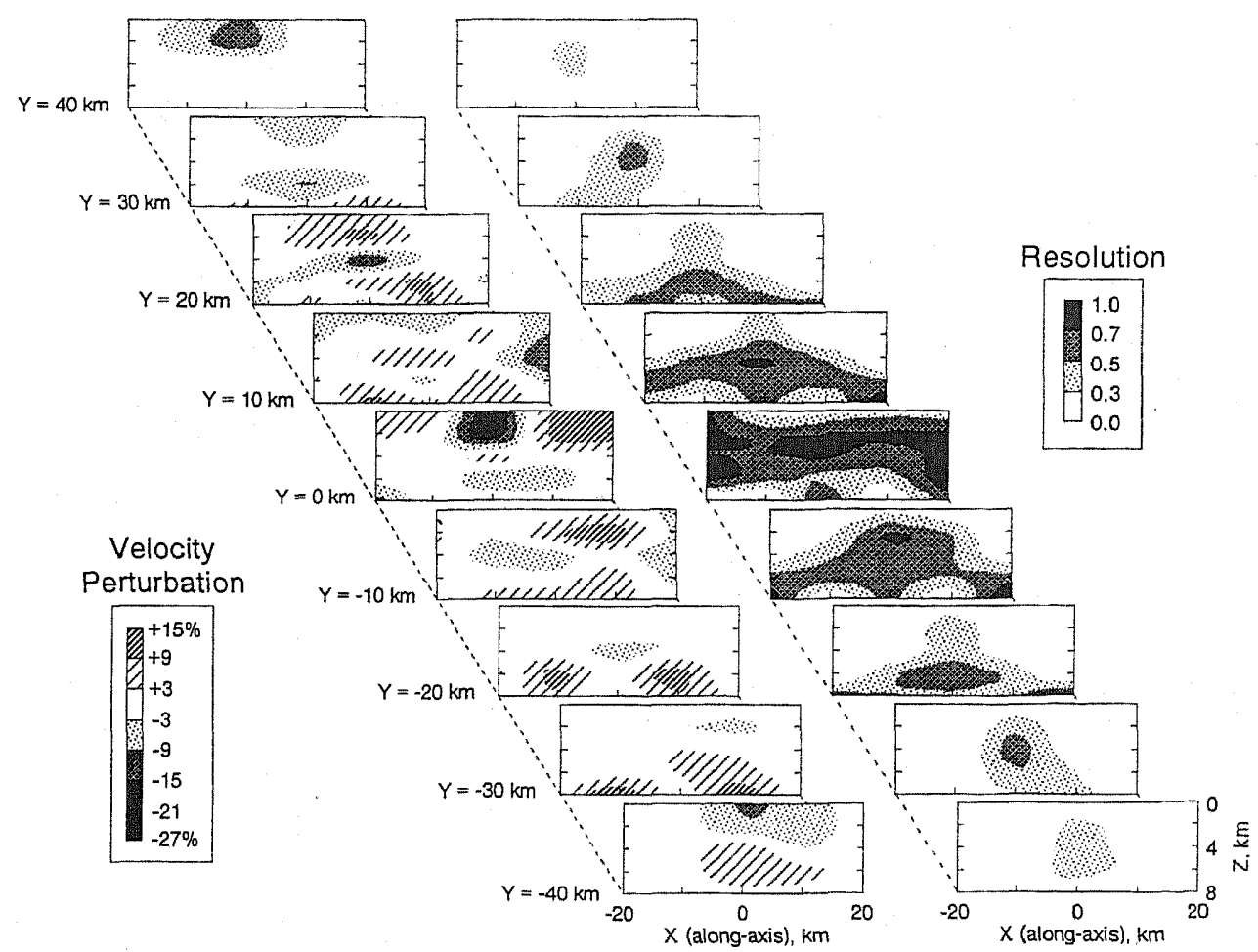

Fig. 12. Vertical sections summarizing inversion 1 results in the along-axis dimension at the across-axis locations of $Y=-40,-30,-20,-10,0,10$, 20, 30, and $40 \mathrm{~km}$. See Fig. 11 for plotting parameters, text for discussion, and Fig. 2(a) for profile locations.

independently-determined estimates, indicates that the along-line velocities are reasonable even though their values of resolution are less than 0.5 (see below). The locations of buried seamounts are especially evident along the axis (Line A) since velocity contours shoal with the $4 \mathrm{~km} / \mathrm{s}$ contour, reaching $Z=0 \mathrm{~km}$ in Fig. 10 . The seamount to the northeast of YB 4 along Line $A$ ( $X=10$ to $20, Y=0$ in Figs. 11 and 12) appears to have higher $\mathrm{P}$-wave velocities than the seamount to the south $(X=-10$ to $-20, Y=0$ in Figs. 11 and 12), and extend off-axis at least $10 \mathrm{~km}$ to the southeast since the anomaly can still be resolved at $X=10, Y=-10$. The velocity variations (up to $15 \%$ greater than the average model) extend to depths of $2-3 \mathrm{~km}$. In contrast, the lowest P-wave velocities (up to $27 \%$ lower than the average model), corresponding to the sedimentary layers at the $4.2 \mathrm{~km}$ depth datum $(Z=0)$, are found in a $10-20 \mathrm{~km}$ zone beneath YB 4 (located at $X=0, Y=0$ in Figs. 10-12).

The imaged velocity structure below $3 \mathrm{~km}$ depth shows substantially more seismic heterogeneity, with resolved velocities ranging up to $7.2 \mathrm{~km} / \mathrm{s}$. The velocity anomalies, however, are more diffuse in shape and, within the limits of uncertainty $( \pm 0.3 \mathrm{~km} / \mathrm{s}$ or $4 \%$ ), not large in magnitude. At depth, resolved portions of the crust appear to be 
slightly more homogeneous, with velocities close to the average model, along the fossil spreading axis than away from it. Along-axis resolution, though, is poorer at depth $(8 \mathrm{~km})$ because of the fewer number of available shots (low DWS). In the across-axis direction (Line B) underlying a 1-2 km layer of higher-than-average velocity crust, is a $2-3 \mathrm{~km}$ thickness of slower-than-average material extending about $20 \mathrm{~km}$ off-axis beneath YB 4; the variations do not appear to extend more than $10 \mathrm{~km}$ to the northeast and southwest ( $X=-10$ to $10, Y=-20$ to 20 in Fig. 11). Well-resolved velocities up to $15 \%$ lower are observed $20 \mathrm{~km}$ to the northwest of Line A $(X=0, Y=20, Z=4$ in Figs. 10-12), but do not directly correlate with known morphological features from Fig. 4.

Velocities very near the bottom of the target volume at $Z=8 \mathrm{~km}$ are in general unreliable, because the estimates result from unknown cumulative effects of possibly spurious estimates for some poorly-constrained shallow nodes. The exceptions to this occur at some places along the shot lines where velocities at shallow levels are well-constrained so that travel times calculated for the shallow portions of the ray paths bottoming at $8 \mathrm{~km}$ depth are accurate. In these areas, notably $(X=-20, Y=-10 ; X=0$, $Y=-10$ to $10 ; X=20, Y=-10$ to 10 in Figs. 11 and 12 ), the determined velocities appear to be close to the average model.

\section{Discussion}

\subsection{Model resolution and stability}

Careful attention was paid in interpreting the resolving capability of the data set and investigating the stability of the estimated model because of the incomplete and inhomogeneous ray coverage within the target volume. The complete resolution matrix at all nodal locations for the preferred source-receiver and velocity parameter configuration (inversion 1) was inspected to correlate the locations of acceptable values of the diagonal element with adjacent small-magnitude, off-diagonal elements. After examination, a resolution (based on the value of the diagonal element) of 0.5 was estimated as the minimum resolution required to ensure that localized averaging resulted in a well-constrained velocity estimate from the inversion. This tactic is similar to that followed by Toomey and Foulger (1989), who quantitatively argued that a finer model parameterization, at the expense of lower resolution of individual velocity parameters, gives a more accurate interpretation of the dimensions of true heterogeneity as long as the effects of off-diagonal elements within the resolution matrix are minimal.

Several inversions were carried out to test model stability, including the effects on the solution of different nodal spacings (by using areal spacings of 8 and $12 \mathrm{~km}$, and depth spacings of 3 and $4 \mathrm{~km}$ ), the choice of datum for the model parameterization (by choosing the datum to be completely within the nominal acoustic basement), and the starting model upon which initial velocity perturbations were calculated (by using a 2D model in which velocities along the shot lines were estimated from air gun and multi-channel reflection data) (Table 1). For comparison among test inversions, the overall reduction in variance is used since all inversions were carried out after similarly applying water path and sediment corrections to the acoustic basement. In general, all inversions converged after 3-4 iterations, and showed final rms travel time residuals 
and overall reductions in variance $(>83 \%)$ which were insignificantly different from inversion 1 at the $95 \%$ confidence level (based on an $F$-test on the ratio of their respective final $\mathrm{rms}$ residuals and variances). Moreover, in areas of good resolving power (resolution $\geq 0.5$ ) no noticeable mismatches could be identified in the patterns of velocity heterogeneity imaged using the various configurations. Mean differences in the absolute velocity between test inversions 3-8 and inversion 1 were less than or equal to the estimated solution error $(0.3 \mathrm{~km} / \mathrm{s})$, implying that the velocity model solutions are indistinguishable from each other.

To test the robustness of the structural model over the upper $2-3 \mathrm{~km}$, which is crucial for the estimation of reliable velocities at deeper levels, an inversion in which the topmost velocities were fixed for all iterations was carried out (inversion 9, Table 1). The topmost velocity structure used was that independently estimated from the air gun and multi-channel reffection data (Katao, 1988). The resulting along- and across-axis structures showed identical velocity contouring for the uppermost crust and consistency in the patterns and magnitudes of the underlying velocity anomalies. Inversion 9 had almost identical values for the final fms travel time residual $(0.07 \mathrm{~s})$ and variance reduction $(85 \%)$ as inversion 1 , and a mean difference in absolute velocity $(0.19 \mathrm{~km} / \mathrm{s})$ smaller than the estimated velocity solution error. Based on this result and other trials using hypothetical structures with different initial velocity models, it was concluded that the P-wave velocities within the uppermost crust are reasonable even though their resolution values are less than 0.5 .

\subsection{Yamato Basin crustal structure}

The results of the Yamato Basin tomographic study, combined with the findings of earlier authors (Ludwig et al., 1975; Katao, 1988; Hirata et al., 1989; Chung et al., 1990 ), suggest that the P-wave velocity structure is similar to that of oceanic crustal structure. In this study, velocities steadily increased to $5.5-6.0 \mathrm{~km} / \mathrm{s}$ over the upper $2-3 \mathrm{~km}$ (gradient $>0.8 \mathrm{~s}^{-1}$ ) along both seismic lines, and were underlain by structure from $3-8 \mathrm{~km}$ depth with more gentle average velocity gradients $\left(0.25 \mathrm{~s}^{-1}\right)$ and velocities extending to $7.2 \mathrm{~km} / \mathrm{s}$. The total thickness for this low gradient layer based on this study is thus at least $5 \mathrm{~km}$. Hirata et al. (1989) has estimated that it could be as large as $10 \mathrm{~km}$ thick. The velocities and velocity gradients describing the observed layers resemble those typically characterizing oceanic seismic layers 2 and 3 (e.g., Raitt, 1963; Spudich and Orcutt, 1980; Purdy and Ewing, 1986). Layer 2 appears to be relatively uniform in thickness and subparallel to the acoustic basement. However, the estimated Moho depth beneath the Yamato Basin, 11-15 km (Katao, 1988; Hirata et al., 1989; Chung et al., 1990), is more than twice that normally found in the deep ocean basin. The increase in crustal thickness is primarily associated with a greater layer 3 thickness, and is consistent with the character of thick crust in other locales (Zehnder and Mutter, 1990). In a compilation of crustal thicknesses in oceanic areas, they found that crustal thickness was strongly correlated with an increase in the thickness of material with velocities greater than $6.5 \mathrm{~km} / \mathrm{s}$, or primarily with seismic layer 3 .

The tomographic solution for the uppermost $8 \mathrm{~km}$ of crust using the DELP-85 shot data agrees with the layered velocity models reported previously by Katao (1988), Hirata et al. (1989), and Chung et al. (1990). Velocities determined for the upper 2-3 km

Vol. 39, No. 3, 1991 
show a layered structure, being remarkably uniform in thickness and described by a single velocity gradient. Although layer 3 was observed to be laterally heterogeneous in this study, the small variations in velocity also suggest that a layered structure can adequately describe the upper $5 \mathrm{~km}$. The similarity in the velocities and velocity gradients imaged along the axis (Line A) with those determined across the axis (Line B) suggests that velocity anisotropy within seismic layer 2 and the upper part of seismic layer 3 is negligible, though because of the azimuthally-distributed data travel time effects resulting from velocity anisotropy may have been smoothed out during tomographic inversion.

Based on the results of the tomographic inversions, it cannot be ascertained whether the imaged crust describes the extrusive and sheeted dike complex thought to compose ocean crust (Petersen et al., 1974; Christensen and Smewing, 1981), or horizontallylayered sills intruded into the crust at the halt of spreading (Hirata et al., 1989). Although velocity anomalies related to buried seamounts extend up to $10 \mathrm{~km}$ from the shot lines, in general the P-wave structure for the upper $2-3 \mathrm{~km}$ is indistinguishable from that describing oceanic seismic layer 2. Similarly at depth, while velocity heterogeneity was imaged, no clear evidence for continuous layering over distances greater than $20 \mathrm{~km}$ can be identified; the pockets of lower velocity material, some of which extend $20 \mathrm{~km}$ off-axis, could be related to thermal anomalies associated with recent crustal intrusions or due to seamount magmatism. There remains the possibility, however, that the data set and model parameterization cannot adequately resolve the wavelength of the features sought, i.e., that the cumulative dimensions of the postulated aggregated sills are greater than the study volume, or that each individual sill is less than the $2 \mathrm{~km}$ nodal spacing. Finally, it is possible that the sill complex cannot be identified diagnostically by changes in P-wave velocity.

\subsection{Formation of Yamato Basin crust}

A survey of crustal investigations at other oceanic locales reveals that thick crustal sequences have also been identified beneath several volcanic passive margins (Mutter et al., 1984, 1988b; Hinz and Krause, 1982), suggesting that the Yamato Basin crust may have been formed under circumstances similar to those that constructed the thick passive margin crusts. A model in which convective partial melting during the first few Ma of rifting produces additional amounts of melt, possibly as great as those due to passive upwelling alone, can lead to the formation of a thick igneous crust (Mutter et al., 1988a). At the initiation of rifting, upwelling of hot asthenosphere into a cool lithosphere creates temperature contrasts sufficient to induce small-scale convection in the upper mantle. Melt production, enhanced by a narrow rifting zone and relatively little lithospheric thinning prior to emplacement, does not sustain itself, however, because lateral temperature gradients are attenuated as the upwelling region broadens. As spreading continues and passive upwelling becomes the primary force responsible for melting (Foucher et al., 1982), the thickness of the igneous complex is predicted to thin to that of normal oceanic crust.

In the case of the Yamato Basin, several factors unique to its formation make the above scenario possible. The proposed rapid formation of the Yamato Basin (perhaps less than $3 \mathrm{Ma}$, Otofuji and Matsuda, 1984) implies that only minimal lithospheric thinning occurred prior to the start of rifting. This, combined with the inference that 
spreading took place over a narrow region (20-km wide Yamato Basin Ridge), suggests conditions favorable for the creation of strong thermal gradients and convective melting. The short timespan of active spreading and existence of small-scale convection also suggests that the melt volume available for crustal construction at the halt of spreading would be greater than that due only to passive upwelling. Thus, a normal oceanic crustal structure would not be expected even beneath the relic spreading axis (Yamato Basin Ridge). The availability of a large supply of magma can explain the range of dates describing the Yamato Seamount chain (6-18 Ma, Kaneoka et al., 1986), some of which appear to postdate the spreading period, and proposed intrusion as crustal sills during the latter stages of spreading (Hirata et al., 1989).

The presence of an additional melt-producing mechanism is also supported by the observed crustal thickness (11-15 km, Katao, 1988; Hirata et al., 1989), which is greater than the thickness predicted by decompression melting $\left(7-11 \mathrm{~km}\right.$ for $\mathrm{Na}_{8.0}=2.08$, using $\mathrm{Na}_{2} \mathrm{O}$ concentrations in clear basalt glass from the Yamato Basin Ridge (Kimura et al., 1987) and crustal thickness curves based on $\mathrm{Na}_{8.0}$ (Klein and Langmuir, 1987)). Such a result implies the existence of an excess volume of melt at a similar degree of melting, as might be expected with convective melting. Differences in source composition, which would affect the predicted crustal thickness curves (Klein and Langmuir, 1987), are thought to be insignificant since the Yamato Basin samples are consistent with their $\mathrm{Na}_{8.0}$ axial depth correlation, and higher mantle temperatures, which would cause greater melting, are not expected because no hot spots are proximal.

\section{Conclusions}

The tomographic inversion of P-wave travel time data from explosive shots for crustal structure beneath the Yamato Basin reveals a structure similar to oceanic crust. Although the configuration of sources and receivers precludes resolution of the entire study volume, an optimally parameterized model together with careful evaluation of model resolution and robustness enables one to maximize the volume of well-constrained structure off the shot lines. The final rms travel time residual for the preferred solution, encompassing a 40 by 20 by $8 \mathrm{~km}$ volume, was $0.07 \mathrm{~s}$ with an average $55 \%$ reduction in variance for each instrument. The structure of the uppermost crust is described by a steady velocity increase to $6 \mathrm{~km} / \mathrm{s}$ over the topmost $2-3 \mathrm{~km}$; the layering appears to subparallel the acoustic basement. Velocity anomalies mapping the locations of buried seamounts extend at least $10 \mathrm{~km}$ from the ridge axis. Below $3 \mathrm{~km}$ depth, resolved portions show more lateral seismic heterogeneity, though these are not large in magnitude; velocities close to the average model are found at the deepest crustal levels. Velocities and velocity gradients are typical of those characterizing oceanic seismic layers 2 and 3 , but the thickness of layer 3 is significantly larger; previous estimates were as great as $10 \mathrm{~km}$ (Katao, 1988; Hirata et al., 1989; Chung et al., 1990). The accompanying increase of layer 3 thickness with increasing crustal thickness agrees with trends observed in oceanic-type crust at other localities. Small-scale convective partial melting within the upper mantle at the onset of back-arc spreading, combined with the short timespan proposed for the formation of the Yamato Basin, may be an effective mechanism in producing the additional amounts of melt needed to form a crust up to $4 \mathrm{~km}$ thicker

Vol. 39, No. 3, 1991 
than that predicted by passive decompression melting alone.

This work was supported by a National Science Foundation Japan Society for the Promotion of Science postdoctoral fellowship (L.S.L.K). We thank DELP-85 scientists and the crew of the Wakashio-maru for the collection of high-quality seismic data, and T. W. Chung for providing the OBS data from the Geophysical Institute. Discussions with K. Johnson and a critical review by $\mathrm{N}$. Hirata helped to improve this manuscript.

\section{REFERENCES}

Aki, K. and W. H. K. Lee, Determination of three-dimensional velocity anomalies under a seismic array using first $\mathrm{P}$ arrival times from local earthquakes 1 . A homogeneous initial model, J. Geophys. Res., 81, 4381-4399, 1976.

Celaya, M. and R. McCabe, Kinematic model for the opening of the Sea of Japan and the bending of the Japanese Islands, Geology, 15, 53-57, 1987.

Chinzei, K., Opening of the Japan Sea and marine biogeography during the Miocene, J. Geomag. Geoelectr., 38, 487-494, 1986.

Christensen, N. I. and J. D. Smewing, Geology and seismic structure of the northern section of the Oman ophiolite, J. Geophys. Res., 86, 2545-2555, 1981.

Chung, T. W., N. Hirata, and R. Sato, Two-dimensional P-and S-wave velocity structure of the Yamato Basin, the southeastern Japan Sea, from refraction data collected by an ocean bottom seismographic array, J. Phys. Earth, 38, 99-147, 1990.

Crosson, R. S., Crustal structure modeling of earthquake data 1. Simultaneous least squares estimation of hypocenter and velocity parameters, J. Geophys. Res., 81, 3036-3046, 1976.

Foucher, J. P., X. LePichon, and J. C. Sibuet, The ocean continent transition in the uniform stretching model: Role of partial melting in the mantle, Philos. Trans. R. Soc. London, Ser. $A, 305,27-43,1982$.

Hayakawa, H. and A. Takemura, The Neogene system in the Yatsuo area Toyama Prefecture, central Japan, J. Geol. Soc. Jpn., 93, 717-732, 1987.

Hayashida, A. and Y. Ito, Paleoposition of Southwest Japan at $16 \mathrm{Ma}$ : Implication from paleomagnetism on the Miocene Ichishi Group, Earth. Planet. Sci Lett., 68, 335-342, 1984.

Hinz, K. and W. Krause, The continental margin of Queen Maud Land/Antarctica: Seismic sequences, structural elements and geological development, Geol. Jahrb., Ser. E, 23, 17-41, 1982.

Hirata, N., H. Tokuyama, and T. W. Chung, An anomalously thick layering of the crust of the Yamato Basin, southeastern Sea of Japan: The final stage of back-arc spreading, Tectonophysics, 165, 303-314, 1989.

Hirata, N., H. Kinoshita, K. Suyehiro, M. Suyemasu, N. Matsuda, T. Ouchi, H. Katao, S. Koresawa, and S. Nagumo, Report on DELP 1985 cruises in the Japan Sea, Part II: Seismic refraction experiment conducted in the Yamato Basin, southeast Japan Sea, Bull. Earthq. Res. Inst., Univ. Tokyo, 62, 347-365, 1987.

Isezaki, N. and S. Uyeda, Geomagnetic anomaly pattern of the Japan Sea, Mar. Geophys. Res., 2, 51-59, 1973.

Jackson, D. D., Interpretation of inaccurate, insufficient and inconsistent data, Geophys. J. $R$. Astron. Soc., 28, 97-109, 1972. 
Jackson, D. D., The use of a priori data to resolve non-uniqueness in linear inversion, Geophys. J. R. Astron. Soc., 57, 137-157, 1979.

Kaneoka, I., K. Notsu, Y. Takigami, K. Fujioka, and H. Sakai, K-Ar, ${ }^{40} \mathrm{Ar}-{ }^{39} \mathrm{Ar}$ age and $\mathrm{Sr}$ isotope studies on volcanic rocks of seamounts from the Japan Sea, in Rock Magnetism and Paleogeophysics, DELP Publication, ed. M. Kono, No. 12, pp. 48-50, Japanese National Communication for the Dynamics and Evolution of the Lithosphere Project (DELP), Tokyo, 1986.

Kasthara, J., M. Takahashi, T. Matsubara, and M. Komiya, Mass storage digital ocean bottom seismometer and hydrophone (DOBSH) controlled by micro-processors using ADPCM voice synthesizing, Bull. Earthq. Res. Inst., Univ. Tokyo, 60, 23-37, 1985.

Kasahara, J., S. Nagumo, S. Koresawa, T. Ouchi, and H. Kinoshita, Seismic activity and crustal structure in back-arc basins near Japanese Islands deduced from ocean bottom seismological observations, J. Phys. Earth, 36, 531-538, 1988.

Kasahara, J,, S. Koresawa, S. Nagumo, T. Daikuhara, T. Hara, and S. Ando, Free fall pop-up OBS (ERI type P-79), Bull. Earthq. Res. Inst., Univ. Tokyo, 54, 515-530, 1979.

Katao, H., Seismic structure and formation of the Yamato Basin, Bull. Earthq. Res. Inst., Univ. Tokyo, 63, 51-86, 1988.

Kimura, M., T. Matsuda, H. Sato, I. Kaneoka, H. Tokuyama, S. Kuramoto, A. Oshida, K. Shimamura, K. Tamaki, H. Kinoshita, and S. Uyeda, Report on DELP 1985 cruises in the Japan Sea Part VII: Topography and geology of the Yamato Basin and its vicinity, Bull. Earthq. Res. Inst., Univ. Tokyo, 62, 447-483, 1987.

Klein, E. M. and C. H. Langmuir, Global correlations of ocean ridge basalt chemistry with axial depth and crustal thickness, J. Geophys. Res., 92, 8089-8115, 1987.

Kong, L. S. L., Variations in structure and tectonics along the Mid-Atlantic Ridge, $23^{\circ} \mathrm{N}$ and $26^{\circ} \mathrm{N}$, Ph. D. thesis, Massachusetts Institute of Technology/Woods Hole Oceanographic Institution, Woods Hole, MA, 341 pp., 1990.

Lallemand, S. and L. Jolivet, Japan Sea: A pull-apart basin?, Earth. Planet. Sci. Lett., 76, 375-389, 1986.

Levenberg, K., A method for the solution of certain non-linear problems in least squares, $Q$. Appl. Math., 2, 164-168, 1944.

Ludwig, W. J., S. Murauchi, and R. E. Houtz, Sediments and structure of the Japan sea, Geol. Soc. Am. Bull., 87, 651-664, 1975.

Marquardt, D. W., An algorithm for least squares estimation of non-linear parameters, J. Soc. Ind. Appl. Math., 11, 431-441, 1963.

Murauchi, S., N. Den, S. Asano, H. Hotta, T. Yoshii, T. Asanuma, K. Hagiwara, K. Ichikawa, T. Sato, W. J. Ludwig, J. I. Ewing, N. T. Edgar, and R. E. Houtz, Crustal structure of the Philippine Sea, J. Geophys. Res., 73, 3143-3171, 1968.

Mutter, J. C., W. R. Buck, and C. M. Zehnder, Convective partial melting 1. A model for the formation of thick basaltic sequences during the initiation of spreading, J. Geophys. Res., 93, 1031-1048, 1988 a.

Mutter, J. C., M. Talwani, and P. L. Stoffa, Evidence for a thick oceanic crust adjacent to the Norwegian margin, J. Geophys. Res., 89, 483-502, 1984.

Mutter, J. C., C. M. Zehnder, and R. L. Larson, The development of extensional systems during rifting of the NW Australian continental margin (abstract), Eos Trans. AGU, 69, 480, 1988 b.

Otofuji, Y. and T. Matsuda, Paleomagnetic evidence for the clockwise rotation of Southwest Japan, Earth Planet. Sci. Lett., 62, 349-359, 1983.

Otofuji, Y. and T. Matsuda, Timing and rotational motion of Southwest Japan inferred from paleomagnetism, Earth Planet. Sci. Lett., 70, 373-382, 1984.

Vol. 39, No. 3, 1991 
Otofuji, Y., T. Matsuda, and S. Nohda, Opening mode of the Japan Sea inferred from the paleomagnetism of the Japan Arc, Nature, 317, 603-604, 1985.

Petersen, J. J., P. J. Fox, and E. Schrieber, Newfoundland ophiolites and the geology of the oceanic layer, Nature, 247, 194-196, 1974.

Purdy, G. M., The correction for travel time effects of seafloor topography in interpretation of marine seismic data, J. Geophys. Res., 87, 8389-8396, 1982.

Purdy, G. M. and J. Ewing, Seismic structure of the ocean crust, in The Geology of North America,Vol. M, The Western North Atlantic Region, ed. P. R. Vogt and B. E. Tucholke', pp. 313-330, Geological Society of America, Boulder, 1986.

Raitt, R. W., The crustal rocks, in The Sea, Vol. 3, ed M. N. Hill, pp. 85-109, John Wiley \& Sons, London, 1963.

Sclater, J. G., D. E. Karig, L. A. Lawver, and K. Louden, Heat flow, depth, and crustal thickness of the marginal basins of the south Philippine Sea, J. Geophys. Res., 81, 309-336, 1976.

Shimamura, H. and T. Asada, A cassette recorder for an ocean bottom seismometer, Geophys. Bull. Hokkaido Univ., 32, 17-24, 1974.

Spudich, P. and J. Orcutt, A new look at the seismic velocity structure of the oceanic crust, Rev. Geophys. Space Phys., 18, 627-645, 1980.

Tamaki, K., Geological structure of the Japan Sea and its tectonic implications, Bull. Geol. Surv. Jpn., 39, 269-365, 1988.

Thurber, C. H., Earth structure and earthquake locations in the Coyote Lake area, central California, Ph. D. thesis, Massachusetts Institute of Technology, Cambridge, MA, 332 pp., 1981.

Tokuyama, H., M. Suyemasu, K. Tamaki, E. Nishiyama, S. Kuramoto, K. Suyehiro, H. Kinoshita, and A. Taira, Report on DELP 1985 cruises in the Japan Sea Part III: Seismic reflection studies in the Yamato Basin and the Yamato Rise area, Bull. Earthq. Res. Inst., Univ. Tokyo, 62, 367-390, 1987.

Toomey, D. R. and G. R. Foulger, Tomographic inversion of local earthquake data from the Hengill-Grensdalur central volcani complex, Iceland, J. Geophys. Res., 94, 17497-17510, 1989.

Wiggins, R. A., The general linear inverse problem: Implications of surface waves and free oscillations for Earth structure, Rev. Geophys. Space Phys., 10, 251-285, 1972.

Zehnder, C. M. and J. C. Mutter, Systematics of thickness variations in ocean crust (abstract), Eos Trans. AGU, 71, 1573, 1990. 